\title{
80 - Análise histológica e imuno-histoquímica de neoplasias melanocíticas cutâneas caninas
}

\author{
1- Universidade Paulista (UNIP), São Paulo-SP \\ 2- Faculdade de Medicina Veterinária e Zootecnia da Universidade de São Paulo, São Paulo-SP
}

As neoplasias melanocíticas são relativamente comuns na espécie canina, correspondendo a cerca de $5 \%$ de todas as neoplasias. Os primeiros relatos da ocorrência deste tipo de processo em animais datam de 1899 e deste entào inúmeros estudos têm sido conduzidos com o objetivo de caracterizar estas neoplasias quanto a sua incidência, comportamento biológico, características histopatológicas e nomenclatura, uma vez que os melanomas e os melanocitomas são considerados neoplasias de diagnóstico extremamente complexo. Partindo-se desta dificuldade realizou-se um estudo retrospectivo de neoplasias melanocíticas cutâneas na espécie canina, analisando suas características histológicas, imuno-histoquímicas e de proliferação celular. Foram analisados 90 casos de neoplasias melanocíticas cutâneas caninas; destas, $61 \%$ foram diagnosticadas como melanocitomas e $39 \%$ como melanomas ou melanomas malignos. As raças caninas mais freqüentemente acometidas pelos melanocitomas foram Cocker Spaniel, Pinscher, Pastor alemão e SRD, na faixa etária de 7 a 12 anos. As lesões foram observadas principalmente na cabeça, acometendo igualmente machos e fêmeas. Já no que se refere aos melanomas, observou-se um maior acometimento de càes das raças Cocker e SRD, na mesma faixa etária. As lesões localizaram-se, sobretudo, na cabeça e membros, acometendo mais freqüentemente machos. As neoplasias foram analisadas quanto às suas características morfológicas e imuno-histoquímicas. A capacidade de proliferação celular foi avaliada pela técnica de AgNOR. Observou-se o predomínio de neoplasias bem diferenciadas, benignas do ponto de vista histológico. O emprego do anticorpo monoclonal Melan A e a avaliação da proliferação celular pela técnica do AgNOR revelaram-se eficientes para o diagnóstico e caracterização dos melanocitomas e melanomas, podendo portanto contribuir para o esclarecimento deste tipo de processo freqüente e ainda capaz de suscitar controvérsias.

\section{1 - Carcinoma broncogênico primário em felino. Relato de caso}

Fragata, F.S. '; Krumenerl Jr, J.L.'; Silva, P.T.D. ${ }^{2}$; Marcondes Santos, M.', Ubukata, R. ${ }^{3}$; Merlo, A. ${ }^{+}$
1- Departamento de Clinica Médica do Hospital Veterinário Sena Madureira, São Paulo-SP

2- Departamento Anátomo-patológico do Hospital Veterinário Sena Madureira, São Paulo-SP

3- Departamento de Oncologia do Hospital Veterinário Sena Madureira, São Paulo-SP

4- Departamento de Clínica Médica e Diretor de internação do Hospital Veterinário Sena Madureira, São Paulo-SP

Os casos de carcinomas pulmonares primários em cães e gatos são relativamente incomuns, podendo acometer cães ao redor de 11 anos de idade e gatos ao redor dos 12 anos de idade, sem predisposição de raça ou sexo. A maioria dos animais vêm a óbito após um curso clínico relativamente curto de aproximadamente dois meses. As manifestações clínicas mais comuns são tosse, dispnéia, inapetência, perda de peso, cianose, insuficiência cardiaca, efusão pericárdica e ocasionalmente osteopatia hipertrófica. O objetivo do presente relato é a descrição de um caso de carcinoma broncogênico em um felino da raça persa, nove anos de idade, há 10 meses com sintomatologia respiratória, sendo tratado em colega. $\mathrm{O}$ animal apresentou-se no Hospital Veterinário Sena Madureira devido dispnéia intensa, com histórico de diagnóstico de bronquite crônica, sendo mantido em gaiola de oxigenoterapia emergencial e vindo à óbito poucos minutos depois. À necrópsia pôde-se observar que todos os lobos pulmonares estavam acometidos por uma superficie irregular, caracterizada por múltiplos nódulos brancoacizentados de consistência firme. Ao corte notou-se intensa congestão, edema, hemorragia e perda de praticamente todo o parênquima normal por essas formações nodulares. No 